ISSN (Print) 0122-5383

ISSN (Online) 2382-4581

Journal of oil, gas and alternative energy sources

\title{
ADHESION FORCES IN ASPHALT MIXTURES AT NANOSCALE
}

\author{
FUERZAS DE ADHESIÓN EN MEZCLAS ASFÁLTICAS \\ A ESCALA NANOMÉTRICA
}

FORÇAS DE ADESÃO EM MISTURAS

ASPHALT NA NANO ESCALA

\begin{abstract}
Yuly-Fernanda López-Contreras ${ }^{1,2 *}$, Arlex Chaves-Guerreroㅇ, Mustaka Akbulut ${ }^{3}$, Zhengdong Cheng ${ }^{3}$, Luis-Javier Hoyos-Marín ${ }^{4}$
\end{abstract}

'Escuela de Ingeniería Química, Universidad Industrial de Santander, Bucaramanga, Colombia, ${ }^{2}$ Corporación para la investigación y Desarrollo en Asfaltos en el Sector Transporte e Industrial, CORASFALTOS, Piedecuesta, Colombia,

${ }^{3}$ Department of Chemical Engineering, Texas A\&M University, College Station, TX, USA.

${ }^{4}$ Ecopetrol S.A - Instituto Colombiano del Petróleo, Km 7 vía Piedecuesta, Santander, Colombia.

e-mail: yulyf.lopez@gmail.com

(Received: Aug. 15, 2016; Accepted: Aug. 16, 2017)

\section{ABSTRACT}

The adhesion forces between bitumen and minerals were measured, using Atomic Force Microscopy (AFM). The AFM enables the study of the interactions between two molecules in a same surface or at interfaces and their behavior. In this case, bitumen samples with different properties were placed in contact with AFM modified tips. The tips were fabricated with minerals found in aggregates used in asphalt mixtures, like silicon dioxide $\left(\mathrm{SiO}_{2}\right)$ and calcium carbonate $\left(\mathrm{CaCO}_{3}\right)$. The work of adhesion was obtained measuring adhesion forces for each bitumen-mineral pair. The direct measurement of forces between asphalt and aggregates at interface level through nanoscopic techniques provides a better insight of the system and its characteristics. This will help to improve the selection of bitumen-aggregate combinations used in asphalt mixtures, obtaining systems with higher bond strength, therefore more resistant to failures.

Keywords: Work of adhesion, Asphalt mixture, AFM, Bitumen, Modified tips, Calcium carbonate, Silicon dioxide, Aggregates.

How to cite: López-Contreras, Y. F., Chaves-Guerrero, A., Akbulut, M., Cheng, Z., Hoyos, Luis-Javier.(2017). Adhesion forces in Asphalt mixtures at nanoscale. CT\&F - Ciencia, Tecnología y Futuro, 7(1), 59 - 72.

*To whom correspondence should be addressed 


\title{
RESUMEN
}

\begin{abstract}
TC as fuerzas de adhesión entre asfalto y diferentes minerales fueron obtenidas empleando el microscopio de fuerza atómica (AFM). El AFM permite el estudio de la interacción entre dos moléculas en la misma superficie o en interfaces y su comportamiento. En esta investigación, varias muestras de asfalto con diferentes propiedades fueron puestas en contacto con puntas modificadas para el AFM. Estas puntas fueron fabricadas con minerales comúnmente encontrados en los agregados empleados en mezclas asfálticas, como son en dióxido de silicio $\left(\mathrm{SiO}_{2}\right)$ y el carbonato de calcio $\left(\mathrm{CaCO}_{3}\right)$. El trabajo de adhesión fue obtenido empleando curvas de fuerza - distancia para cada sistema asfalto-mineral. La medición directa de las fuerzas desarrolladas entre asfalto y agregado en la interface empleando técnicas nanoscopicas proveen un mejor entendimiento del sistema y sus características. Esto, sin duda alguna contribuirá en la selección de combinaciones asfalto - agregado empleadas en mezclas asfálticas que desarrollen enlaces más fuertes, produciendo sistemas más resistentes a las diferentes fallas relacionadas al fenómeno de adhesión que pueden generarse en pavimentos asfálticos.
\end{abstract}

Palabras clave: Trabajo de adhesión, Mezclas asfálticas, AFM, Asfalto, Puntas modificadas, Carbonato de calcio, Dióxido de silicio, Agregados.

\section{RESUMO}

s forças de adesão entre o asfalto e diversos minerais foram obtidas através microscópio de força
atômica (AFM) $\mathrm{O} A \mathrm{AFM}$ possibilita o estudo entre duas moléculas na mesma superfície ou em interfaces
e seu comportamento. Várias amostras de asfalto com diversas propriedades foram colocadas em

Palavras-chave: Trabalho de adesão, Misturas asfálticas, AFM, Asfalto, Pontas modificadas, Carbonato de cálcio, Dióxido de silício, Adições. 


\section{INTRODUCTION}

Adhesiveness of a bitumen-aggregate system is one of the fundamental properties that affect asphalt pavements performance. Low adhesion causes bitumen detachment from the aggregate surface leading to severe distresses such as moisture damage and cracking in asphalt mixture. Annually, large amounts of money are disbursed for maintenance and rehabilitation of roads all over the world. According to the Office of Highway Policy Information (2017) and U.S Department of Transportation, in 2015 the United States of America spent more than US $\$ 51$ billion in highway maintenance . America's roads have a significant rehabilitation needs due to poor conditions. One out of every five miles of highway pavements in USA is in poor condition. Nowadays, even to repair the existing highways $\$ 420$ billion are needed (ASCE, 2017). Other emerging countries, although in less quantity, also spend billions of dollars annually on road maintenance as reported by the Organization for Economic Co-operation and Development (OECD). Efficient transport infrastructure provides economic and social benefits to both advance and emerging economies by improving market accessibility and productivity, ensuring balanced regional economic development, creating employment, promoting labor mobility and connecting communities.

For asphalt pavements, mineral aggregates are mixed with bitumen in the production of asphalt mixtures; their interaction with other substances such as water or chemical modifiers affects the overall performance of the mixture and, in turn, of the pavement structure. The properties of the interactions developed between molecules of bitumen and stone aggregates can be related to thermodynamic quantities. The Gibbs free energy is associated to the formation of the adhesive bonds, or to the excessive free energy of the system associated with the surface or the interface. Surface energy is also associated with the work of adhesion as the energy required to detach surfaces. Based on the relationship between the Gibss free energy of adhesion, work of adhesion, and contact angle through the YoungDupré equation, several researchers measured the surface energy of bitumen and aggregates to predict the performances of bitumen - aggregate interface of asphalt mixtures (Bhasin, 2006; Bhasin, Dallas, \& Little, 2007; Cheng, Little, Lytton, \& Holste, 2001; Hefer \&
Little, 2005, 2005; Howson, Masad, Bhasin, Little, \& Lytton, 2011; Miller, Little, Bhasin, Gardner, \& Herbert, 2012; Tan \& Guo, 2013; Wei, Dong, Li, \& Zhang, 2014). However, these theories were developed based on homogeneous surfaces and pure materials. Based on results obtained from several researches, Clint (2001) concludes that although the use of surface free energy to obtain the work of adhesion correlates well with data from measured strength of adhesion for specific systems, some simple solid-liquid systems fail to show a good correlation between measured strength of adhesion and interfacial work of adhesion.

Bitumen, also called asphalt binder, is a complex mixture of different organic hydrocarbons that can be grouped in fractions of saturates, aromatics, resins, and asphaltenes containing heteroatoms. These fractions can physically and chemically interact with each other providing different properties and a complex behavior to bitumen (Lesueur, 2009). On the other hand, aggregates are a composite comprised of hundreds of particles with random variability in mineralogy. The main minerals identified in aggregates are silicon dioxide $\left(\mathrm{SiO}_{2}\right)$, calcium carbonate $\left(\mathrm{CaCO}_{3}\right)$ followed by aluminum, iron, calcium, magnesium, sodium oxides, among others present in minor quantities (Miller et al., 2012). Therefore, the principal components of asphalt mixtures are heterogeneous.

Some research works have been recently carried out to study surface and adhesion forces, using microscopic and sub-microscopic techniques in order to improve the basic knowledge of this phenomenon elucidating the impact of the heterogeneity of the systems. For instance, Drelich and Wang (2011) calculated diffuse-layer charge density and potential for natural minerals, using atomic force microscopy (AFM) measurements and the DLVO model, concluding that adhesion forces are dominated by the heterogeneity of the surface, which differs from the present thermodynamic theory .

Other studies have focused on providing insights into the mechanical and adhesion properties of asphalt binder and aggregates, assessing the moisture susceptibility on asphalt mixtures, the wetting behavior between bitumen and different mineral surfaces, and the adhesion of different components of bitumen like saturates, aromatics, resins and asphaltenes, using atomic force 
microscopy (Al-Rawashdeh \& Sargand, 2014; Allen, Little, \& Bhasin, 2012; Arifuzzaman, 2010; Pauli, Grimes, Cookman, \& Huang, 2014; Tarefder \& Zaman, 2011; Tarefder \& Zaman, 2010). Moreover, researchers led by IBM Zurich have used the AFM and scanning tunneling microscopy (STM) to collected data of individual asphaltenes molecules, providing information about the molecular structures, aromaticity, typical types and locations of heterocycles (Schuler et al., 2017; Schuler, Meyer, Peña, Mullins, \& Gross, 2015). Their findings provide the foundation to understand the chemistry and physics of asphaltenes, very important for interfacial interactions and engineering applications (Pauli et al., 2014). However, none of them studies the adhesion phenomena at interface level, or constitutes a complete study of bitumen - aggregate adhesion at interface using AFM. Nor there is an approach to establish correlations to predict the interfacial behavior taking into account the chemical composition of contact surfaces at molecular level.

This study investigates the interaction between bitumen and aggregates at interface level measuring adhesion forces between bitumen samples and minerals of different chemical composition, present in aggregates used in asphalt mixtures with an AFM. Tips modified with $\mathrm{SiO}_{2}$ and $\mathrm{CaCO}_{3}$ particles are used to directly measure the adhesion force between asphalt and minerals. Adhesion force allows calculating the work of adhesion between materials. The paper also describes how the chemical composition of materials may influence the adhesive force developed.

\section{EXPERIMENTAL DEVELOPMENT}

\section{Materials}

Three different bitumen samples labeled A, B, and C, with different chemical composition and properties, were used in this research. The samples were provided by the Colombian Institute of Petroleum, ICP, ECOPETROL S.A. (Colombia) and used as received.

Table 1 with the main properties of bitumen samples shows that the bitumen A has a penetration of 60-70, similar to bitumen used in conventional asphalt mixtures. Bitumen $\mathrm{B}$ and $\mathrm{C}$ with different properties such as lower penetration and higher asphaltene content were selected to study the influence of bitumen properties in adhesion.

\section{Atomic Force Microscopy (AFM)}

In his study were employed two types of acquisition modes: the tapping mode to characterize bitumen surface and the contact mode to determine the adhesion forces. The AFM measurements were performed on a Bruker Dimension Icon AFM (Materials Characterization Facility (MCF) at Texas A\&M University, TX). In both cases the same bitumen sample preparations were performed.

\section{Bitumen sample preparation}

Stock solutions of $200.0 \mathrm{~g} / \mathrm{L}$ of bitumens were prepared by dissolving each bitumen in pure toluene; these were left overnight to form a homogeneous solution. Then bitumen films were prepared by the

Table 1. Properties and Composition of Bitumen Samples.

\begin{tabular}{|ccccc|}
\hline \multirow{2}{*}{ Property } & \multicolumn{3}{c|}{ Bitumen sample } \\
& Standard & A & B & C \\
\hline Penetration @ $25^{\circ} \mathrm{C}(\mathrm{mm} / 10)$ & ASTM D5 & 71.2 & 5.2 & 34.0 \\
\hline Viscosity @ $80^{\circ} \mathrm{C}(\mathrm{cP})$ & ASTM D2196 & 21.7 & 2960.6 & 12.2 \\
\hline Saturates (\%) & ASTM D4124 & 16.1 & 10.6 & 51.6 \\
\hline Aromatics (\%) & ASTM D4124 & 50.9 & 46.6 & 25.9 \\
\hline Resins (\%) & ASTM D4124 & 25.8 & 22.1 & 10.3 \\
\hline Asphaltenes (\%) & ASTM D4124 & 7.2 & 20.6 & 0.21 \\
\hline Nitrogen (wt. \%) & ASTM D3228 & 0.17 & 1.92 & 1.93 \\
\hline Sulfur (wt. \%) & ASTM D4294 & 1.63 & 0.4 & 1.3 \\
\hline Acid number (TAN) & ASTM D974 & 0.9 & 2.19 \\
\hline Colloidal index & N/A & 3.29 & 3.30 \\
\hline
\end{tabular}


spin coating of each stock solution diluted to $100 \mathrm{~g} / \mathrm{L}$ over a glass microscope slide. The samples were left in a desiccator previously purge with nitrogen for at least 24 hours before imaging and force measurements to prevent contamination by dust and humidity. This also assures the evaporation of the solvent from the bitumen samples and the formation of a smooth and homogeneous bitumen film.

\section{Topographic measurement}

The tapping mode was used because the contact mode could not generate consistent topographic images of viscoelastic samples. Triangular silicon nitride cantilevers with silicon nitride tips (Digital Instruments, $\mathrm{NJ}$ ) were used to obtain topographic images from the surfaces of the samples. The cantilevers had a spring constant of $0.12 \mathrm{nN} / \mathrm{m}$ and the tip was $10 \mathrm{~nm}$ in diameter.

The topographic images of bitumen surfaces were obtained at room temperature with the respective phase image. Initial settings of AFM were as follows: scan size $=500 \mathrm{~nm}$; scan rate $=1.0 \mathrm{~Hz}$; samples $/$ lines $=512$; integral gain $=0.5$; proportional gain $=5.0$; amplitude set point $=371.2 \mathrm{mV}, \mathrm{Z}$ Limit $=9.557 \mu \mathrm{m}$. Parameters were then adjusted during imaging to obtain better quality images.

\section{Adhesion force measurements}

To measure the total adhesive force between the bitumen and the mineral (the so-called pull-off force), the tip of the cantilever has to be functionalized with the material of interest. Silicon cantilevers modified with $\mathrm{SiO}_{2}$ and $\mathrm{CaCO}_{3}$ particles (Novascan Technologies, Ames, IA USA) were used to obtain force curves between minerals and the bitumen surfaces. The particles were $5 \mu \mathrm{m}$ in diameter, and the cantilevers had a spring constant of $5.4 \mathrm{~N} / \mathrm{m}$ (see Figure 1).

The force curves were acquired in contact mode based upon the surface analysis. The testing procedure for adhesion force studies is the following: first the cantilever is calibrated with a standard surface for its spring constant and resonant frequency. Then several force curves are acquired at different locations over the sample surface with a set of appropriate operational parameters. Average values and standard deviation of adhesion force were reported for comparison. After each measurement, a contact mode force curve on a clean,

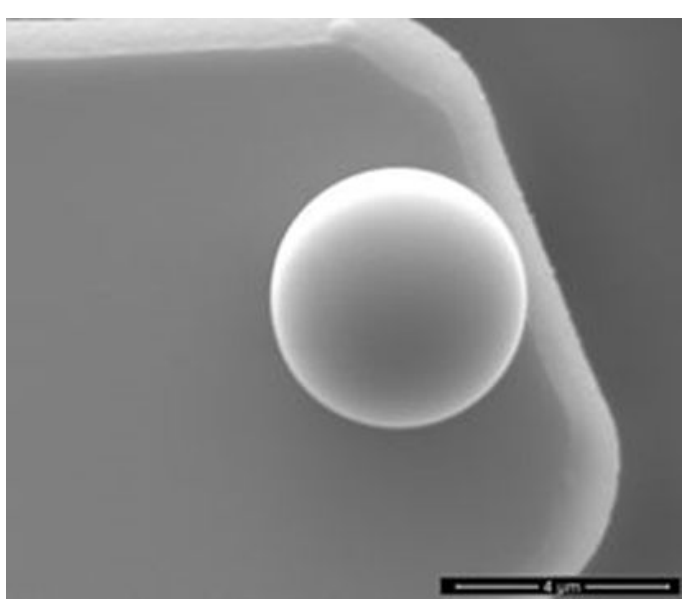

Figure 1. SEM image of $\mathrm{SiO}_{2}$ particle modified tip.

hard standard surface was conducted to evaluate the usefulness of the tip for another measurement with the same bitumen. Then, the cantilever was calibrated again with the standard surface and non-significant changes of values measured for spring constant and resonant frequency were observed. Additionally, after each test, tip images with scanning electron microscopy (SEM) were acquired to make sure that the tip had no defects and was not contaminated by the bitumen sample. However, a new tip was used in force measurement for each type of bitumen.

Initial settings of AFM in contact mode to record force-distance curves were the following: $Z$-scan size $=$ $0 \mu \mathrm{m}$; scan rate $=1.0 \mathrm{~Hz}$; samples/line: 256 , deflection set point $=3.5 \mathrm{~V}$, integral gain $=2.0$, proportional gain $=5.0, \mathrm{Z}$ limit $=9.557 \mu \mathrm{m}$. The resulting images and force curves were evaluated using Nanoscope Analysis 1.40. All experiments were conducted in air at room temperature.

A force distance curve for bitumen $\mathrm{A}$ with $\mathrm{SiO}_{2}$ tip obtained at room temperature is shown in Fig. 2. The $\mathrm{x}$-axis in Figure 2 represents the vertical motion of the cantilever tip and the y-axis represents the forces (repulsive and attractive forces) between the bitumen and the tip molecule. The arrow indicates the direction and tip approach during measurement. When the tip is away from the bitumen surface there is no interaction between its molecule and the bitumen molecule, therefore the force is zero. As the tip approaches the surface and the distance between them decreases, the attractive force between the tip and the sample surface becomes larger allowing the contact with the bitumen 
surface causing a jump to contact force. Once the cantilever reaches a target value, the tip is retracted by the actuator with a loading force, but still in contact with the bitumen surface. Finally, the cantilever with tip is pulled off the bitumen sample and the force curves back to zero value.

To take into account all forces acting on the bitumenmineral system, the model proposed by DerjagunMuller-Toporov (DMT) to compute the work of adhesion was used (Eq. 1):

$$
\text { DMT model: } \quad F_{a}=2 \pi R W^{a}
$$

where $F_{a}$ is the adhesion force, $W^{a}$ is the work of adhesion, and $R$ is the particle radius.

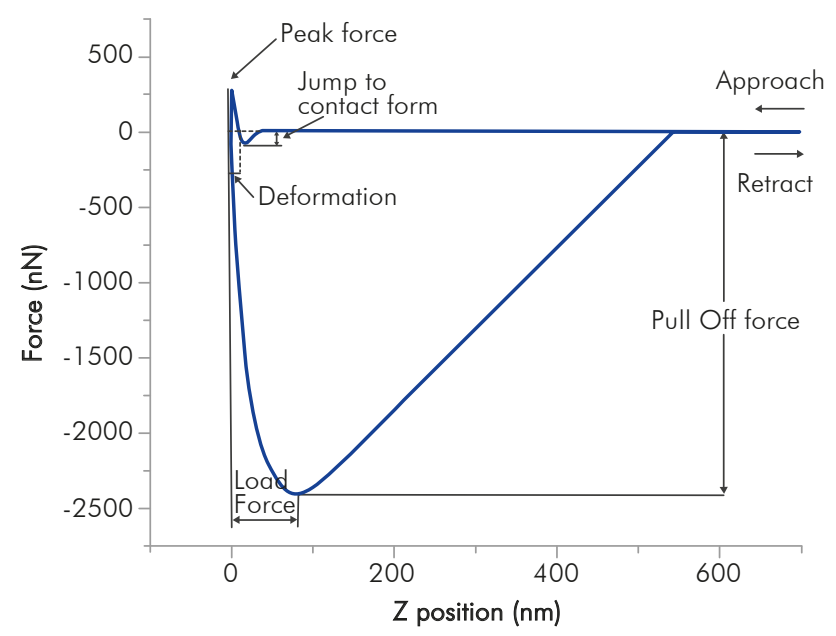

Figure 2. AFM force curve plot for bitumen $\mathrm{A}$ with $\mathrm{SiO}_{2}$ tip at room temperature, depicting Jump to contact Force, applied loading force, Load Force, and Pull off force, the minimum point on the retraction curve, just before pull off.

\section{RESULTS AND DISCUSSION}

\section{Bitumen morphology}

Figures 3a), c) and e) correspond to topographic images of bitumen samples A, B, and C, respectively. The imaged area is $15 \times 15 \mu \mathrm{m}$, and the $\mathrm{z}$-scale is around $11 \mathrm{~nm}$ for bitumen samples $A$ and $C$, and 42 $\mathrm{nm}$ for sample B. Figs. 3b), d), f) are phase images. Some bitumens can present three different phases as shown in Figure 3d): a disperse phase also called catana phase, represented by a succession of pale and dark lines often referred to as bees or bee structure; a periphase that is immediately around the catana phase, and the paraphase that is adjacent to the periphase with a darker shade (Masson, Leblond, \& Margeson, 2006). The catana phase was identified only for bitumen sample B. Samples A and C did not show the catana phase in its morphology. Instead, their images showed dispersed domains in bitumen A, and flake-like domains of different sizes in bitumen C. The topographic images, indicate that the disperse domains in bitumen A were slightly depressed $(1-2 \mathrm{~nm})$ from the surface (Fig. 3 a), while for bitumen $\mathrm{C}$ the disperse phase protruded slightly form its surface (Fig. 3 e).

The phase images show that bitumens are not homogeneous materials and not all the hydrocarbons present in bitumen are mutually soluble at room temperature. The phase detection also provides information about bitumen rheology and composition (Masson et al., 2006). All bitumens studied have different composition (see Table 1), and show particular arrangements based on Figures $3 \mathrm{~b}$ ), d), and f). This would suggest that the composition is important in determining the bitumen structure and morphology. Several researchers have studied the direct relationship between bitumen morphology and chemical composition using the AFM (Loeber, Sutton, Morel, Valleton, \& Muller, 1996; Pauli, Branthaver, Robertson, Grimes, \& Eggleston, 2001). Pauli et al. (2001) found that a bitumen with a multi-phase structure contained around $13-20 \% w t / w t$ of asphaltenes. In an early work on bitumen with AFM, Loeber et al. (1996) attributes the catana phase to asphaltenes, with the highest molecular weight and the most aromatic compounds in bitumen. Other researchers studied the interactions of asphaltenes in heavy crude oil and concluded that at lower asphaltene concentration, small aggregates could be formed while at higher concentration the aggregates form asphaltene clusters (Rahimi \& Gentzis, 2006). Our results are similar; the sample with the highest asphaltenes concentration is showing a catana phase.

Also, the phase images in Figure 3 highlight domains with different viscoelastic properties or stiffness, providing a map of stiffness variations on the sample surface. A stiffer region has a more positive phase shifts than a less stiff region, hence appears brighter in phase image (Masson, Leblond, Margeson, \& Bundalo-Perc, 2007). Figure $3 \mathrm{~b}$ ) for bitumen A shows disperse domains that appear darker than the continuous phase, which means that in these areas the material is softer. Figure 3 f) shows a surface with brighter domains for bitumen $\mathrm{C}$. 


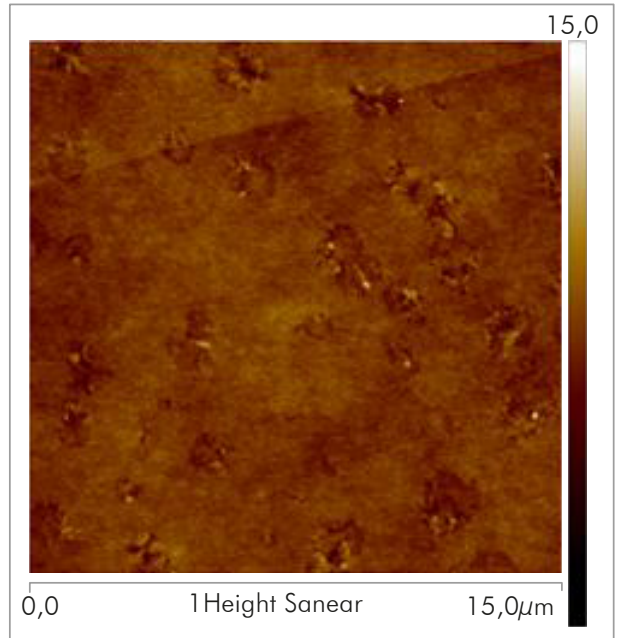

(a)

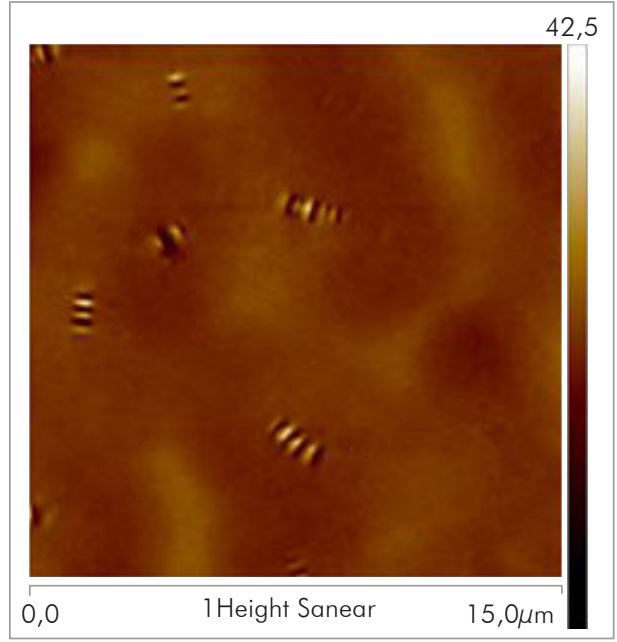

(c)

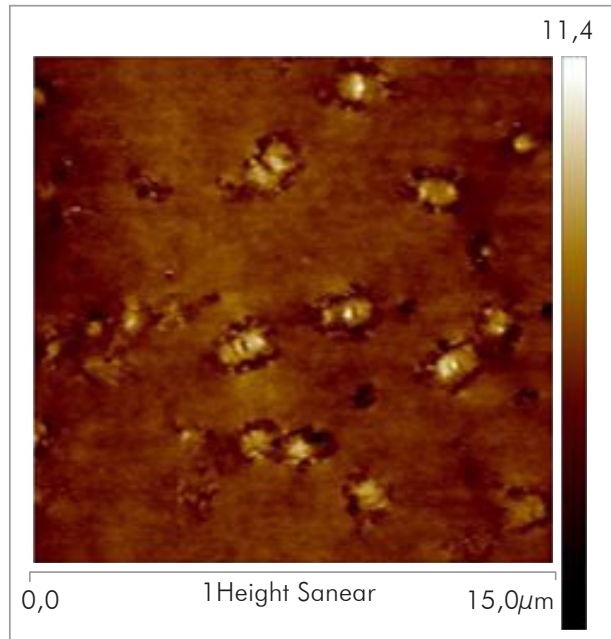

(e)

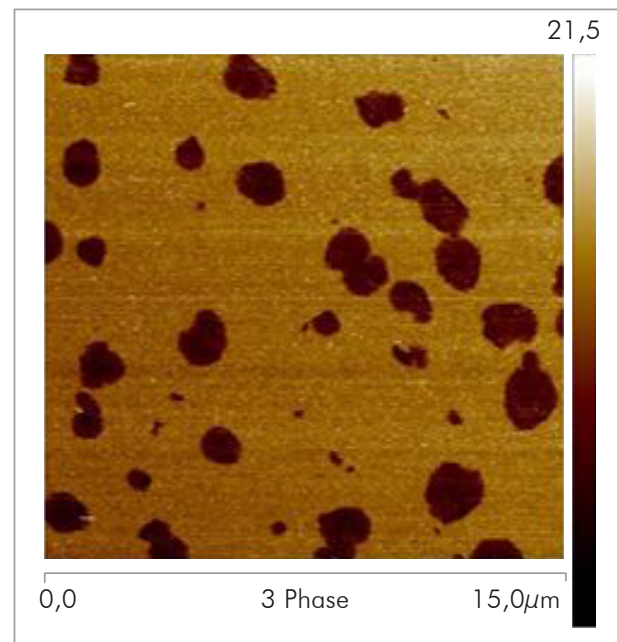

(b)

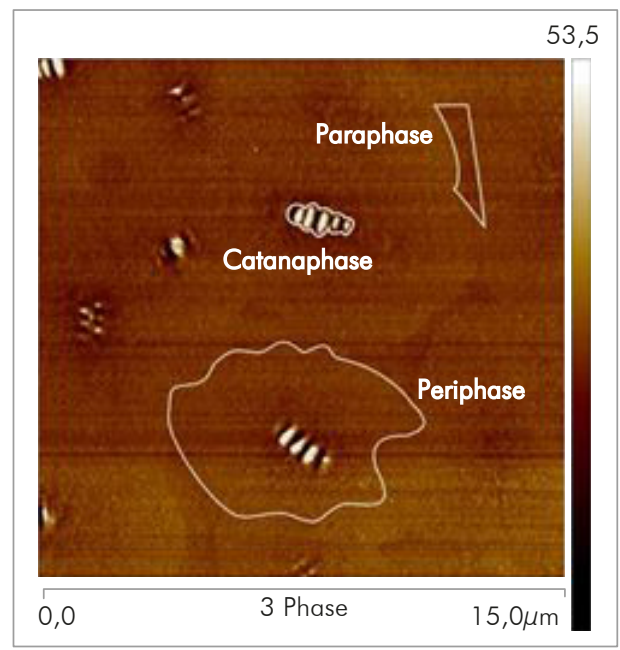

(d)

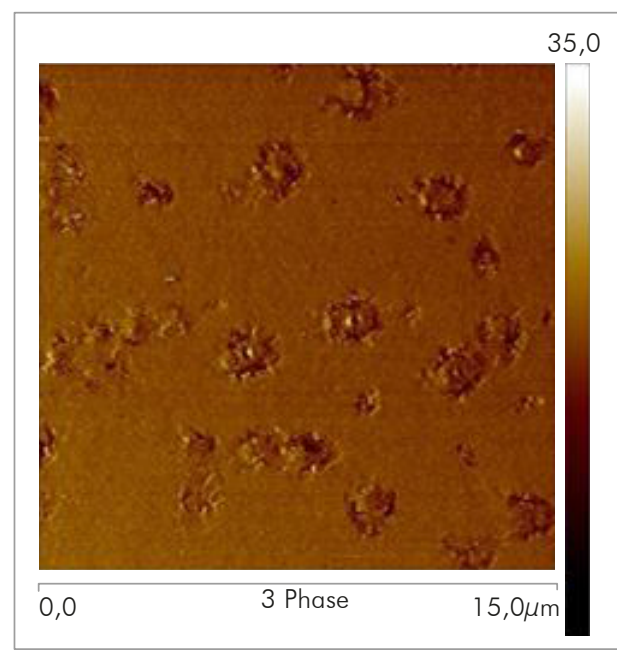

(f)

Figure 3. Topography and phase images of bitumen samples. a) and b) are topographic and phase images for bitumen A, respectively. c) and d) are topographic and phase images for bitumen B, respectively showing the multiple phases for this sample. e) and f) are topographic and phase images for bitumen C, respectively. 
For bitumen B, the extent of the shift variations is much higher than those observed for the other samples; hence, the catana phase can be assigned to the most rigid and polar bitumen fraction. Factors that influence stiffness of an organic material like bitumen include the size and flexibility of the bitumen compounds and their mutual interactions related to the functional groups and the polarity provided by metals content. The phase images concurred with the viscous nature of these materials, which is congruent with bitumen properties as shown in Table 1, such as penetration and viscosity.

The colloidal index (CI) is used to determine the colloidal stability of bitumens, expressed by the following relationship:

$$
C I=(\text { resins }+ \text { aromatics }) /(\text { saturates }+ \text { asphaltenes })
$$

For bitumens $\mathrm{A}, \mathrm{B}$, and $\mathrm{C}$ the colloidal indexes are $3.29,2.19,3.30$, respectively. Bitumens $\mathrm{A}$ and $\mathrm{C}$ with almost the same CI show structures with two principal domains while sample B with a lower CI shows a multi-phase structure with the presence of the catana phase. According to the colloidal structural model, asphaltenes are stabilized by resins in a sea of aromatics and saturated hydrocarbons. A higher colloidal index is proper of a more stable colloid structure where asphaltenes are more peptized by resins in the oil base medium (Loeber, Muller, Morel, \& Sutton, 1998). Based on images obtained through SEM and AFM, Loeber et al. (1996) concluded that bitumen with high asphaltene content and lower colloidal index is made of individual domains associated to asphaltene particles.

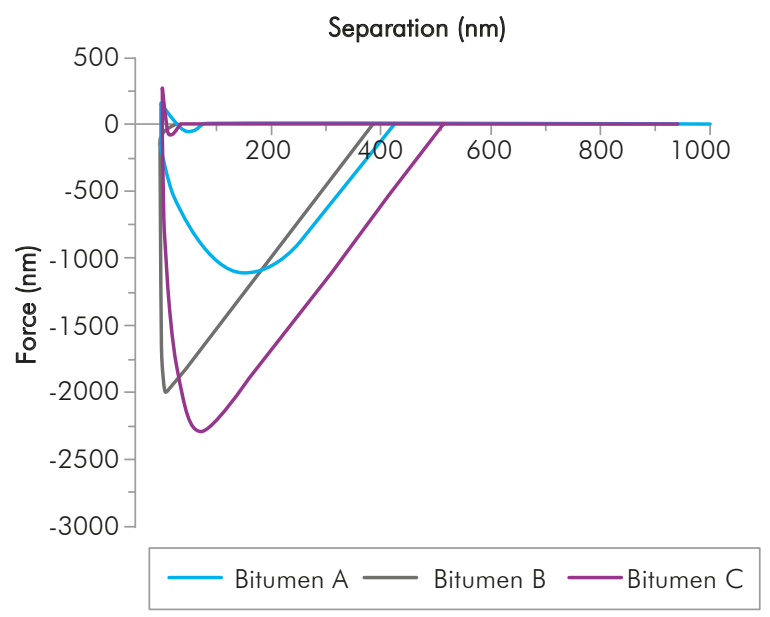

AFM images showed the structural arrangement of different bitumens. The results establish the existence of a direct relationship between chemical composition and bitumen structure. High asphaltene content lead to the formation of the bee structure or the catana phase. Moreover, the high colloidal index of bitumen samples A and $\mathrm{C}$ suggests that their structures are more stable than that of bitumen $\mathrm{B}$, reinforcing the idea of a relationship between chemical composition and structure.

\section{Adhesion measurement with AFM}

Figure 4 shows an average of force - distance curves for each bitumen with $\mathrm{SiO}_{2}$ and $\mathrm{CaCO}_{3}$ modified tips. Young's modulus for bitumen samples can be estimated using the retract curve (Lyne, Wallqvist, \& Birgisson, 2013). Modulus calculation is related to the deformation shown in Figure 2 and the relevant tip radius. The distance from the point, where the force is zero to the peak force along the approach curve corresponds to the maximum sample deformation as displayed in Figure 2. It was found that the maximum deformation corresponds to sample $\mathrm{A}$ followed by samples $\mathrm{C}$ and $\mathrm{B}$, respectively. Therefore, sample A has a lower Young modulus than samples B and C, being B the highest. Moreover, from Figure $3 \mathrm{~b}$ ), d), and f), Young's modulus increases when the color of the image goes from dark to light. Most of the variations in Young's modulus found from phase images within each bitumen are due to differences between the phase's concentration, including phase separation viewed in the catana phase (bees), and at smaller degree due to variations within each type of phase. The results are in good agreement with bitumens properties as shown in Table 1.

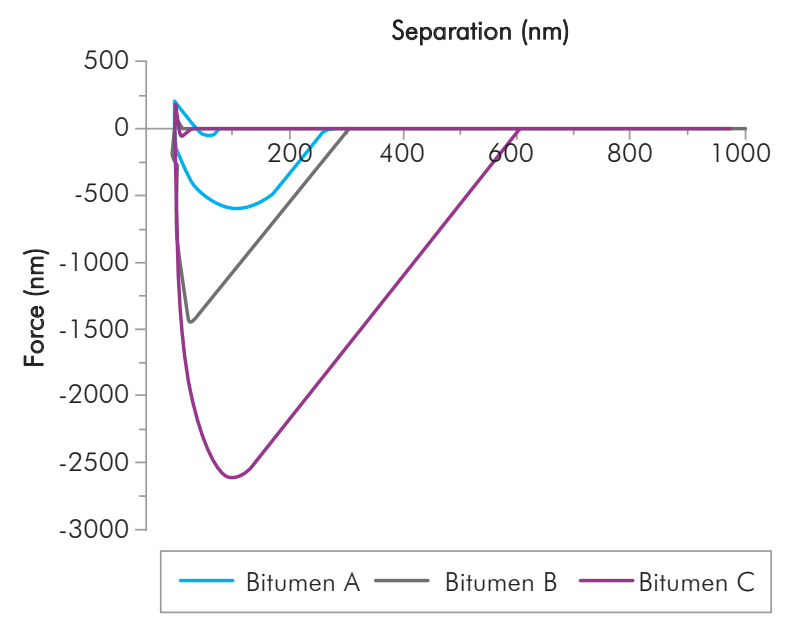

Figure 4. Force curve images for: a) $\mathrm{SiO}_{2}$ modified tip in contact with bitumen samples; b) $\mathrm{CaCO}_{3}$ modified tip in contact with bitumen samples. 
Based on the contact mechanics theory, the work of adhesion was calculated from pull of force (Little, Bhasin, \& Hefer, 2006). Table 2 shows the average work of adhesion calculated using Eq. 1, and the standard deviation (SD) for each set of measurements.

Table 2. Work of Adhesion between bitumen and mineral modified tips

\begin{tabular}{|c|c|c|c|c|}
\hline \multirow{2}{*}{ Bitumen } & \multicolumn{4}{|c|}{ Work of Adhesion $\left(\mathrm{mJ} / \mathrm{m}^{2}\right)$} \\
& \multicolumn{2}{|c|}{ SiO2 } & \multicolumn{2}{c|}{ CaCO3 } \\
\cline { 2 - 5 } & Avg. & SD & Avg & SD \\
\hline A & 67.78 & 8.20 & 42.43 & 4.36 \\
\hline B & 105.26 & 3.02 & 70.30 & 7.24 \\
\hline C & 109.34 & 10.41 & 142.39 & 8.53 \\
\hline
\end{tabular}

The values obtained for the work of adhesion calculated from force-distance curves vary from 42.43 to $142.39 \mathrm{~mJ} / \mathrm{m} 2$. As shown in Table 2, there is a significant difference between the work of adhesion measured for samples A and B with the two tips. It can be seen that the work of adhesion between samples $\mathrm{A}, \mathrm{B}$, and $\mathrm{SiO}_{2}$ tip is higher than the work of adhesion for the same bitumen samples with the $\mathrm{CaCO}_{3}$ tip. A different behavior was found for sample $\mathrm{C}$. Opposite to the trend observed for the other samples, the work of adhesion obtained for bitumen $\mathrm{C}-\mathrm{CaCO}_{3}$ tip was higher than with the $\mathrm{SiO}_{2}$ tip. Recent results reported by Li et al. (2017), showed higher work of adhesion for bitumen with $\mathrm{SiO}_{2}$ than for bitumen with $\mathrm{CaCO}_{3}(\mathrm{Li}$, Yang, \& Tan, 2017). Adhesive forces measured between $\mathrm{SiO}_{2}$ and bitumen were in the range of $1500 \mathrm{nN}$; values closed to the $1200 \mathrm{nN}$ reported in Figure 4 for bitumen A, with similar properties than the sample used by Li et al. (2017). These findings are congruent with data showed in Figure 4 and Table 2, for bitumen $\mathrm{A}$ and $\mathrm{SiO}_{2}$, suggesting that consistent force measurements were obtained.

Moreover, regardless of the mineral considered, the work of adhesion was higher for bitumen C. This indicates that bitumen $\mathrm{C}$ develops a stronger interaction with both $\mathrm{SiO}_{2}$ and $\mathrm{CaCO}_{3}$ surfaces. For an asphalt mixture, a high work of adhesion is related to a relatively low sensitivity to moisture damage and to be durable (Bhasin, Howson, Masad, Little, \& Lytton, 2007). Therefore the work of adhesion between bitumen and aggregate has to be as high as possible. Miller et al. (2012) studied the impact of minerals on bond strength in asphalt mixture by means of the universal sorption device and the surface energy of bitumen. The results showed that there are specific minerals-bitumen combinations, although very limited in number, which are thermodynamically resistant to debonding even in the presence of water. However, the stability depends on the surface chemistry of the bitumen as well as the mineral. Some similar behavior was found for calcium carbonate and for specific bitumen. Calcite in the carbonate group developed a thermodynamically favored bond with bitumen, compared with the competing bond between aggregate and water (Miller et al., 2012). This could explain the high value for the work of adhesion obtained for bitumen $\mathrm{C}$ and $\mathrm{CaCO}_{3}$.

Tensile strength is used to determine the asphalt mixture susceptibility to moisture damage through the mechanical properties of the asphalt mixture. The tensile strength is directly related to the adhesion strength between bitumen and aggregate at interface level by the ratio between dry and wet samples. Bagampadde, Isacsson, and Kiggundu (2006) related these mechanical properties of asphalt mixtures in dry condition to the acidity of bitumen. Bitumen with high acid number exhibits high mechanical properties, like resilient modulus and tensile strength in dry condition. However, the influence of bitumen acidity on tensile strength in the presence of water were aggregate specific. Therefore, the adhesive strength depends on the mineral as well as the surface chemistry of the bitumen. Bitumen $\mathrm{C}$ has a high acid number that could be related to the high values of adhesion force measured in dry condition with both minerals.

Aggregates used to produce asphalt mixtures are not purely composed of one mineral type. Results are generally related to the fact that there are localized regions on aggregate surfaces with some minerals developing inherently resistant bonds with specific bitumens. Hundreds of measurements of aggregate, bitumen, and asphalt mixture properties done by different researchers indicate that none of the aggregatebitumen combinations analyzed thus far were resistant to stripping (Little \& Jones IV, 2003; Lyne, Redelius, Collin, \& Birgisson, 2013; Lytton, Masad, Zollinger, Bulut, \& Little, 2005; Moghadas Nejad, Azarhoosh, Hamedi, \& Azarhoosh, 2012). Therefore, it is important to highlight that typical bitumen used in hot asphalt mixtures correspond to a bitumen with similar properties as of sample A. From results, it can be observed that 
this sample showed the lower work of adhesion with $\mathrm{SiO}_{2}$ and $\mathrm{CaCO}_{3}$ tips, which suggests that weak bonds can be developed between bitumen with both minerals. These weak bonds are easily broken under the effect of water and the traffic load leading to moisture damage. Distresses caused by moisture damage such as stripping are one of the major failures present in asphalt pavements.

A further analysis was conducted, based on the adhesion experimental data of this study. The relationship between the work of adhesion obtained and the chemical composition were investigated using single regression analysis, respectively. The nitrogen and acidity content has a fairly good linear relationship with the work of adhesion obtained for bitumen and both $\mathrm{SiO}_{2}$ and $\mathrm{CaCO}_{3}$ modified tips.

Bitumen is composed of non-polar hydrocarbons, which may also contain heteroatoms as part of these molecules such as nitrogen $(\mathrm{N})$. These heteroatoms are present in small amounts, but it was found that give certain polarity to bitumen introducing a significant effect on properties of bitumen and its interaction with aggregate surfaces. Certain functional groups in bitumen which includes nitrogen such as pyridine and pyrrolic types were reported, strongly adsorbed and resistant to water displacement (Curtis, Ensley, \& Epps, 1993; Hefer $\&$ Little, 2005). Several moisture damage inhibiting agents have been developed based on nitrogen content fractions, to improve adhesion between bitumen and aggregates (Plancher \& Petersen, 1982; Sawatzky, Clelland, \& Farnand, 1994; Treybig \& Chang, 1988). This could be related to the high work of adhesion developed between bitumen $\mathrm{C}$ with the highest nitrogen content and minerals, followed by bitumens $\mathrm{B}$ and $\mathrm{A}$. However, this finding requires more evaluation.

Although further analysis to include more measurements will help to validate the finding of this work, data obtained follows the behavior observed by previous researchers. Moreover, further research using the AFM to study adhesion at molecular scale will help to state correlations predicting the interfacial behavior, including the chemical composition, physical characteristics, and surface morphology of contact surfaces such as aggregates and bitumen used in asphalt mixtures.

\section{CONCLUSIONS}

- The AFM was used to characterize the morphologies of the three bitumen samples with different chemical composition obtained from different crude oil sources. The typical bee structure was observed for one out of the three bitumen binders studied. The periphase surrounding the catana phase could be identified for sample B. Samples A and C showed dispersed domains of different sizes. The asphaltene content seems to be related to the morphological structure of bitumens, as mentioned by other researchers.

- The work of adhesion between bitumen and particles of $\mathrm{SiO}_{2}$ and $\mathrm{CaCO}_{3}$ attached to the AFM cantilever was also studied using the AFM. Bitumen samples A and $\mathrm{B}$ showed a higher work of adhesion with $\mathrm{SiO}_{2}$ than with $\mathrm{CaCO}_{3}$ while an opposite behavior was observed for bitumen $\mathrm{C}$, which developed a higher work of adhesion with $\mathrm{CaCO}_{3}$ than with $\mathrm{SiO}_{2}$. Future work with more minerals and real aggregates samples have to be conducted to improve the selection of materials for asphalt mixtures. This will help to reduce the main distresses present in pavements.

- The correlation between the experimental data obtained for the work of adhesion and the chemical composition of bitumen samples were further investigated. Results suggest that there is a good correlation between the nitrogen content in bitumen and the strength of the bonds formed with minerals. This findings help to better understand the adhesion phenomena between bitumen and different minerals present in asphalt mixtures. Although the data points are the limitation of current research, more bitumen samples will be analyzed to validate the findings of this study.

- The implementation of techniques using modified tips with minerals present in aggregates surface such as the ones used in this work with AFM, will serve to bridge this gap of knowledge between the current state of knowledge and current state of practice to properly measure adhesion and to identify better bitumen-aggregate combinations. 


\section{ACKNOWLEDGEMENTS}

The authors acknowledge the financial support received from the Colombian Institute of Petroleum (ICP, ECOPETROL S.A), and COLCIENCIAS; the technical support of Corporation for Research and Development in Asphalt in the Transport and Industry Sector (CORASFALTOS), and Texas A\&M University for tests execution.

\section{REFERENCES}

Al-Rawashdeh, A., \& Sargand, S. (2014). Performance Assessment of a Warm Asphalt Binder in the Presence of Water by Using Surface Free Energy Concepts and Nanoscale Techniques. Journal of Materials in Civil Engineering, 26(5), 803-811. DOI: doi:10.1061/(ASCE) MT.1943-5533.0000866

Allen, R Grover, Little, D., \& Bhasin, A. (2012). Structural Characterization of Micromechanical Properties in Asphalt Using Atomic Force Microscopy. Journal of Materials in Civil Engineering, 24(10), 1317-1327. DOI: doi:10.1061/ (ASCE)MT.1943-5533.0000510

Arifuzzaman, MD. (2010). Nano-Scale Evaluation of Moisture Damage in Asphalt. Doctor of Philosophy Civil Engineering. The University of New Mexico, Albuquerque, New Mexico, 249.

ASCE. (2017). Infraestructure Report Card. Technical Report. American Society of Civil Engineers.

Bagampadde, U., Isacsson, U., \& Kiggundu, B. M. (2006). Impact of bitumen and aggregate composition on stripping in bituminous mixtures. Materials and Structures, 39(3), 303-315. DOI: 10.1007/s11527-005-9040-5

Bhasin, Amit. (2006). Development of Methods to Quantify Bitumen-Aggregate Adhesion and Loss of Adhesion due to Water. Doctor of Philosophy Civil Engineering. Texas A\&M University, College Station, TX, 146.

Bhasin, Amit, Dallas, N., \& Little, P.E. (2007). Characterization of Aggregate Surface Energy Using the Universal Sorption Device. Journal of Materials in Civil Engineering, 19(8), 8. DOI: https://doi.org/10.1061/(ASCE)08991561(2007)19:8(634)
Bhasin, Amit, Howson, Jonathan, Masad, Eyad, Little, Dallas, \& Lytton, Robert. (2007). Effect of Modification Processes on Bond Energy of Asphalt Binders. Transportation Research Record: Journal of the Transportation Research Board, 1998, 29-37. DOI: 10.3141/1998-04

Clint, John H. (2001). Adhesion and components of solid surface energies. Current Opinion in Colloid \& Interface Science, 6(1), 28-33. DOI: http://dx.doi.org/10.1016/S13590294(00)00084-4

Curtis, Christine W., Ensley, Kaith, \& Epps, Jon. (1993). Fundamental Properties of Asphalt-Aggregate Interactions Including Adhesion and Absorption. Technical Report. National Research Council.

Cheng, DingXin, Little, D., Lytton, Robert, \& Holste, James. (2001). Surface Free Energy Measurement of Aggregates and its Application to Adhesion and Moisture Damage of Asphalt-Aggregate Systems. Paper presented at the 9th Annual Symposium of the International Center for Aggregate Research. College Station, TX.

Drelich, Jaroslaw, \& Wang, Yu U. (2011). Charge heterogeneity of surfaces: Mapping and effects on surface forces. Advances in Colloid and Interface Science, 165(2), 91-101. DOI: http://dx.doi.org/10.1016/j.cis.2010.12.009

Hefer, A., \& Little, D. (2005). Adhesion in bitumen-aggregate systems and quantification of the effects of water on the adhesive bond. Technical Report. Texas Transportation Institute.

Hefer, A., \& Little, D. (2005). Towards quantification of adhesion and water stripping in bituminous materials using modern surface energy theory. Paper presented at the 24th Southern African Transport Conference Pretoria, South Africa.

Howson, Jonathan, Masad, Eyad, Bhasin, Amit, Little, Dallas, \& Lytton, Robert. (2011). Comprehensive analysis of surface free energy of asphalts and aggregates and the effects of changes in $\mathrm{pH}$. Construction and Building Materials, 25(5), 2554-2564. DOI: http://dx.doi.org/10.1016/j. conbuildmat.2010.11.098

Lesueur, Didier. (2009). The colloidal structure of bitumen: Consequences on the rheology and on the mechanisms of bitumen modification. Advances in Colloid and Interface Science, 145(1-2), 42-82. DOI: http://dx.doi.org/10.1016/j. cis.2008.08.011 
Li, Yujie, Yang, Jie, \& Tan, Ting. (2017). Adhesion between Modified Binders and Aggregate Minerals at Ambient Conditions Measured with Particle-Probe Scanning Force Microscopes. Journal of Materials in Civil Engineering, 29(8), 04017068. DOI: doi:10.1061/(ASCE)MT.19435533.0001887

Little, D., Bhasin, A., \& Hefer, A. (2006). Using surface energy measurements to select materials for asphalt pavements. Technical Report. Texas Transportation Institute.

Little, Dallas, \& Jones IV, David R. (2003). Chemical and mechanical processes of moisture damage in hot-mix asphalt pavements. Paper presented at the Moisture Sensitivity of Asphalt Pavements: A National Seminar. San Diego, California.

Loeber, L., Muller, G., Morel, J., \& Sutton, O. (1998). Bitumen in colloid science: a chemical, structural and rheological approach. Fuel, 77(13), 1443-1450. DOI: http://dx.doi. org/10.1016/S0016-2361(98)00054-4

Loeber, L., Sutton, O., Morel, J., Valleton, J. M., \& Muller, G. (1996). New direct observations of asphalts and asphalt binders by scanning electron microscopy and atomic force microscopy. Journal of Microscopy, 182(1), 32-39. DOI: 10.1046/j.1365-2818.1996.134416.x

Lyne, Åsa Laurell, Wallqvist, Viveca, \& Birgisson, Björn. (2013). Adhesive surface characteristics of bitumen binders investigated by Atomic Force Microscopy. Fuel, 113(0), 248-256. DOI: http://dx.doi.org/10.1016/j.fuel.2013.05.042

Lyne, ÅsaLaurell, Redelius, Per, Collin, Måns, \& Birgisson, Björn. (2013). Characterization of stripping properties of stone material in asphalt. Materials and Structures, 46(1-2), 47-61. DOI: 10.1617/s11527-012-9882-6

Lytton, R., Masad, Eyad, Zollinger, C., Bulut, R., \& Little, D. (2005). Measurements of surface energy and its relationship to moisture damage. Technical Report. Texas Transportation Institute.

Masson, J. F., Leblond, V., \& Margeson, J. (2006). Bitumen morphologies by phase-detection atomic force microscopy. Journal of Microscopy, 221(1), 17-29. DOI: 10.1111/j.13652818.2006.01540.x

Masson, J. F., Leblond, V., Margeson, J., \& Bundalo-Perc, S. (2007). Low-temperature bitumen stiffness and viscous paraffinic nano- and micro-domains by cryogenic AFM and PDM. Journal of Microscopy, 227(3), 191-202. DOI: 10.1111/j.1365-2818.2007.01796.x

Miller, Clint, Little, Dallas, Bhasin, Amit, Gardner, Nathan, \& Herbert, Bruce. (2012). Surface Energy Characteristics and Impact of Natural Minerals on Aggregate-Bitumen Bond Strengths and Asphalt Mixture Durability. Transportation Research Record: Journal of the Transportation Research Board, 2267, 45-55. DOI: 10.3141/2267-05

Moghadas Nejad, F., Azarhoosh, A. R., Hamedi, Gh H., \& Azarhoosh, M. J. (2012). Influence of using nonmaterial to reduce the moisture susceptibility of hot mix asphalt. Construction and Building Materials, 31, 384-388. DOI: http://dx.doi.org/10.1016/j.conbuildmat.2012.01.004

Office of Highway Policy Information, FHWA. (2017). Highway Statistics 2015. [On-line]. [Consulted: July 11, 2017]. Available in: <https://www.fhwa.dot.gov/ policyinformation/statistics/2015/pdf/hf2.pdf $>$.

Pauli, A. T. , Branthaver, J. F., Robertson, R. E. , Grimes, W. , \& Eggleston, C. M. . (2001). Atomic Force Microscopy Investigation of SHRP Asphalts. Paper presented at the Heavy oil and resid compatibility and stability Symposium.

Pauli, T, Grimes, W, Cookman, A, \& Huang, S. (2014). Adherence Energy of Asphalt Thin Films Measured by Force-Displacement Atomic Force Microscopy. Journal of Materials in Civil Engineering, 26(12), 04014089. DOI: doi:10.1061/(ASCE)MT.1943-5533.0001003

Plancher, H., \& Petersen, J.C. (1982). United States of America Patent No. US 4325738.

Rahimi, Parviz M., \& Gentzis, Thomas. (2006). The Chemistry of Bitumen and Heavy Oil Processing. In C. S. Hsu \& P. R. Robinson (Eds.), Practical Advances in Petroleum Processing. New York, NY. Springer New York, 597-634.

Sawatzky, H., Clelland, F.I., \& Farnand, B.A. (1994).

Schuler, Bruno, Fatayer, Shadi, Meyer, Gerhard, Rogel, Estrella, Moir, Michael, Zhang, Yunlong, ... Gross, Leo. (2017). Heavy Oil Based Mixtures of Different Origins and Treatments Studied by Atomic Force Microscopy. Energy \& Fuels, 31(7), 6856-6861. DOI: 10.1021/acs. energyfuels. $7 \mathrm{~b} 00805$ 
Schuler, Bruno, Meyer, Gerhard, Peña, Diego, Mullins, Oliver C., \& Gross, Leo. (2015). Unraveling the Molecular Structures of Asphaltenes by Atomic Force Microscopy. Journal of the American Chemical Society, 137(31), 98709876. DOI: $10.1021 /$ jacs.5b04056

Tan, Yiqiu, \& Guo, Meng. (2013). Using surface free energy method to study the cohesion and adhesion of asphalt mastic. Construction and Building Materials, 47, 254-260. DOI: http://dx.doi.org/10.1016/j.conbuildmat.2013.05.067

Tarefder, R, \& Zaman, A. (2011). Characterization of Asphalt Materials for Moisture Damage Using Atomic Force Microscopy and Nanoindentation. In K. Gopalakrishnan, B. Birgisson, P. Taylor \& N. Attoh-Okine (Eds.), Nanotechnology in Civil Infrastructure. Ames, Iowa. Springer Berlin Heidelberg, 237-256.

Tarefder, Rafiqul A., \& Zaman, Arif M. (2010). Nanoscale Evaluation of Moisture Damage in Polymer Modified Asphalts. Journal of Materials in Civil Engineering, 22(7), 714-725. DOI: doi:10.1061/(ASCE)MT.19435533.0000072

Treybig, D.S., \& Chang, D. (1988). United States of America Patent No. US 4,724,003.

Wei, Jianming, Dong, Fuqiang, Li, Yanan, \& Zhang, Yuzhen. (2014). Relationship analysis between surface free energy and chemical composition of asphalt binder. Construction and Building Materials, 71(0), 116-123. DOI: http://dx.doi. org/10.1016/j.conbuildmat.2014.08.024

\section{AUTHORS}

\section{Yuly Fernanda López Contreras}

Affiliation: Escuela de Ingeniería Química, Universidad Industrial de Santander, Bucaramanga, Colombia.

e-mail: yulyf.lopez@gmail.com

\section{Arlex Chaves Guerrero}

Affiliation: Escuela de Ingeniería Química, Universidad Industrial de Santander, Bucaramanga, Colombia.

e-mail: achavesg@uis.edu.co

\section{Mustaka Akbulut}

Affiliation: Department of Chemical Engineering, Texas $A \& M$

University, College Station, TX, USA..

e-mail:makbulut@mail.che.tamu.edu

\section{Zhengdong Chengz}

Affiliation: Department of Chemical Engineering, Texas A\&M University, College Station, TX, USA

e-mail: zcheng@mail.che.tamu.edu

\section{Luis Javier Hoyos Marín}

Affiliation: Ecopetrol S.A - Instituto Colombiano del Petróleo, Piedecuesta, Colombia

e-mail: luis.hoyos@ecopetrol.com.co 
